\title{
PERSEPSI SISWA JURUSAN TKR TERHADAP STANDAR KESEHATAN DAN KESELAMATAN KERJA
}

\author{
Jeans Herbert ${ }^{1}$, Wowo S. Kuswana. ${ }^{2}$, Sunarto H. Untung ${ }^{3}$ \\ Departemen Pendidikan Teknik Mesin \\ Universitas Pendidikan Indonesia \\ Jl. Dr. Setiabudhi No. 207 Bandung 40154 \\ zendilen89@gmail.com
}

\begin{abstract}
ABSTRAK
Tujuan penelitian ini adalah untuk menggambaran pemahaman siswa di SMK Negeri 6 Bandung tentang kesehatan dan keselamatan kerja ketika berada di lapangan/workshop, standar kesehatan dan keselamatan kerja yang memenuhi standar di industri, dan pemahaman siswa terhadap memahami rambu-rambu kesehatan dan keselamatan kerja, upaya penanganan dan penanggulangan kecelakaan kerj. Metode penelitian yang digunakan adalah metode deskriptif eksploratif. Pengumpulan data yang digunakan adalah wawancara, dokumentasi, observasi, dan kuesioner. Sampel diambil sebanyak 20 siswa secara sampling purposive dari total populasi siswa kelas XII TKR SMK Negeri 6 Bandung. Hasil penelitian menunjukkan tingkat pemahaman siswa jurusan TKR terhadap standar kesehatan dan keselamatan kerja pada mata diklat memperbaiki roda dan ban, secara umum memiliki gambaran pada kategori baik. Kesehatan dan Keselamatan Kerja yang terdapat disekolah sudah sesuai dan memenuhi standar kesehatan dan keselamatan kerja di industri. Tingkat pemahaman siswa kelas XII TKR terhadap rambu-rambu kesehatan dan keselamatan kerja dan upaya penanganan dan penanggulangan kecelakaan kerja yang kemungkinan terjadi di lapangan sudah sesuai dan baik.
\end{abstract}

Kata kunci: standar, TKR, K-3, bengkel, industri.

\begin{abstract}
The purpose of this research is to gain a real picture of the level students understanding in SMK 6 Bandung about occupational health and safety when in the field/workshop, standards occupational health and safety students be compared at industry and an overview of students' understanding about the signs of occupational health and safety and when the students handling and prevention of occupational accidents are likely to happen in the field. The method used in this research are descriptive exploratory method. Data collection is interview, documentation, observations, and questionnaires. Samples take as many as 20 student's purposive sampling of the total student population Class XII SMK TKR 6 Bandung. The results showed that the level of understanding of the students majoring in TKR on occupational health and safety standards in fixing wheels and tires study, generally have a good overview of the category. Occupational health and safety at school are similar with occupational health and safety standards in the industry. Level of understanding of class XII students TKR against signs of health and safety and the handling and prevention of occupational accidents that may occur in the field is fit and well.
\end{abstract}

Keywords: TKR, safety and health standards, workshop, industry.

\footnotetext{
${ }^{1}$ Mahasiswa Departemen Pendidikan Teknik Mesin FPTK UPI

${ }^{2}$ Dosen Departemen Pendidikan Teknik Mesin FPTK UPI

${ }^{3}$ Dosen Departemen Pendidikan Teknik Mesin FPTK UPI
} 


\section{PENDAHULUAN}

Pendidikan penting bagi sebuah bangsa karena didalam suatu pendidikan terdapat nilai-nilai yang baik, luhur, pantas dan indah untuk dikembangkan dalam semua aspek kehidupan. Sekolah Menengah Kejuruan (SMK) sebagai salah satu tumpuan di bidang pendidikan guna terciptanya SDM Indonesia yang berkualitas. SMK adalah suatu lembaga pendidikan kejuruan teknologi yang mempersiapkan para lulusannya menjadi tenaga kerja tingkat menengah yang kreatif, terampil dan produktif serta mempunyai rasa tanggung jawab. Kesehatan dan keselamatan kerja merupakan tugas semua orang yang bekerja, termasuk siswa pada saat melaksanakan praktek di tempat kerja (Depdiknas, 2005). Namun pada kenyataannya masih banyak sekolah yang belum memberikan perhatian yang serius terhadap pentingnya pemahaman K3. Kaitan penerapan K3 dengan perilaku siswa ketika melaksanakan dan berada di ruang praktikum belum berjalan dengan baik. Hal ini terlihat pada saat siswa praktek seperti pada saat mempelajari mata diklat memperbaiki roda dan ban. Mata diklat memperbaiki roda dan ban merupakan salah satu contoh mata pelajaran yang dipelajari siswa pada saat duduk di kelas XII. Proses memperbaiki roda dan ban ini memang rawan terjadi kecelakaan yang menyebabkan siswa terkadang keseleo saat salah dalam penggunaan peralatan praktikum dan cedera kaki atau tangan karena tertimpa ukuran dan berat ban

Kebiasaan antara perilaku siswa terhadap standar K3 di sekolah seharusnya bisa membuat siswa mudah untuk beradaptasi dengan standar K3 di industri. Disinilah pentingnya dilakukan penelitian mengenai standar kesehatan dan keselamatan kerja yang berlaku di SMK dan untuk mengetahui seberapa jauh pemahaman siswa dengan standar K3 yang terdapat di sekolah. Standar K3 di sekolah harusnya sesuai dengan standar di industri baik dari segi peraturan, rambu-rambu maupun perlengkapannya (Anizar, 2009).

Pendidikan menengah kejuruan merupakan pendidikan menengah yang mempersiapkan siswa terutama untuk bekerja dalam bidang tertentu sesuai dengan keahlian masing-masing. Sekolah menengah kejuruan adalah suatu bentuk pendidikan formal yang menyelenggarakan pendidikan kejuruan pada jenjang pendidikan menengah sebagai lanjutan dari SMP/MTs atau bentuk lain yang sederajat atau lanjutan dari hasil belajar yang diakui sama/setara SMP/MTs. Permendiknas Nomor 22 Tahun 2006 mengemukakan bahwa sekolah menengah kejuruan bertujuan untuk meningkatkan kecerdasan, pengetahuan, kepribadian, akhlak mulia, serta keterampilan peserta didik untuk hidup mandiri dan mengikuti pendidikan yang lebih lanjut sesuai dengan program kejuruannya. Sekolah Menengah Kejuruan (SMK) menyelenggarakan program diklat 
yang sesuai dengan jenis lapangan kerja. Program tersebut senantiasa harus disesuaikan dengan perkembangan lapangan pekerjaan. Jenis bidang dan program keahlian ditetapkan oleh Direktorat Jenderal Pendidikan Dasar dan Menengah.

Substansi atau materi pendidikan yang dipelajari SMK pada dasarnya berupa kompetensi-kompetensi yang dinilai penting dan perlu bagi siswa dalam menjalani kehidupan, sesuai dengan tuntutan zaman. Kompetensi yang dimaksud meliputi kompetensi yang dibutuhkan untuk menjadi manusia yang bermoral, berakhlak, berbudi pekerti, berpengetahuan, berketerampilan, berseni dan berperilaku sehat dalam kehidupan masyarakat. Masa pendidikan pada SMK umumnya adalah tiga tahun sesudah pendidikan dasar dan dapat diperpanjang menjadi empat tahun. Perpanjangan masa pendidikan tersebut hanya dimungkinkan bila didasarkan atas tuntutan pencapaian kompetensi standar yang harus dikuasai pada suatu program (Sudjana, 2005).

Teknik kendaraan ringan merupakan kompetensi keahlian bidang teknik otomotif yang menekankan keahlian pada bidang penguasaan jasa perbaikan kendaraan ringan. Kompetensi keahlian teknik kendaraan ringan menyiapkan peserta didik untuk bekerja pada bidang pekerjaan jasa perawatan dan perbaikan kendaraan di dunia usaha/industri. Siswa TKR/Otomotif yang mengambil Keahlian Teknik Kendaraan Ringan secara khusus bertujuan untuk memperoleh keterampilan, pengetahuan dan sikap agar kompeten dari pendidiknya.

Adapun kompetensi keahlian yang akan mereka peroleh antara lain: memahami dasar-dasar mesin, memahami proses-proses dasar pembentukan logam, menjelaskan proses mesin konversi energi, menginterpretasikan gambar teknik, menggunakan peralatan dan perlengkapan di tempat kerja, menggunakan alat-alat ukur (measuring tools), menerapkan prosedur keselamatan, kesehatan kerja dan lingkungan tempat kerja, memperbaiki sistem hidrolik dan kompresor udara, melaksanakan prosedur pengelasan, pematrian, pemotongan dengan panas dan pemanasan, melakukan overhaul sistem pendingin dan komponen-komponennya, memelihara/servis sistem bahan bakar bensin, memperbaiki sistem injeksi bahan bakar diesel, pemeliharaan/servis engine dan komponenkomponennya, memperbaiki unit kopling dan komponen-komponen sistem pengoperasian, memelihara transmisi, memelihara unit final drive/garden, memperbaiki poros penggerak roda, roda dan ban, memperbaiki sistem rem, memperbaiki sistem kemudi, memperbaiki sistem suspensi, memelihara baterai, memperbaiki kerusakan ringan pada rangkaian/ sistem kelistrikan, pengaman dan kelengkapan tambahan, memperbaiki sistem pengapian, memperbaiki sistem starter dan pengisian, memelihara/servis sistem AC (Air Conditioner). 
Siswa-siswa TKR ini diharapkan mampu bersaing dan bekerja langsung dalam dunia industri tempat mereka berada begitu mereka lulus dari SMK. Pendidikan dan pengalaman yang diperoleh oleh siswa TKR selama sekolah akan menjadi dasar agar mereka lebih kompeten nantinya.

Kaitan mata diklat ini dengan pembahasan utama ini yaitu tentang K3 terkait dengan proses dan prosedur praktek pengerjaannya. Dalam mata diklat memperbaiki roda dan ban, siswa dituntut untuk sangat berhati-hati agar tidak terjadi kecelakaan kerja yang tidak diinginkan. Contohnya dalam proses kompetensi dasar, siswa diarahkan untuk memeriksa roda dan ban. Ketika memeriksa roda, dilakukan pelepasan roda dan ban sesuai prosedur yang ada dan sesuai dengan standar kesehatan dan keselamatan kerja. K3 yang diterapkan ini diharapkan bisa menghindarkan siswa dari kecelakaan kerja yang mungkin bisa terjadi seperti tangan dan kaki tertimpa roda yang berat, keseleo karena salahnya posisi tubuh ketika bekerja dan penggunaan peralatan yang salah ketika praktik. Kecelakaan kerja yang seperti itu tentu saja tidak diharapkan oleh siapapun baik dari pihak sekolah, keluarga, ataupun siswa praktek itu sendiri (Kuswana, 2015).

Filosofi tentang kesehatan dan keselamatan kerja merupakan pemikiran dan upaya dalam menjamin keutuhan dan kesempurnaan. Filosofi tentang kesehatan dan keselamatan kerja, meliputi: tenaga kerja dan manusia pada umumnya, baik jasmani maupun rohani dan hasil karya dan budaya menuju masyarakat adil, makmur, dan sejahtera. Kesehatan kerja adalah suatu keadaan seorang pekerja yang terbebas dari gangguan fisik dan mental sebagai akibat pengaruh interaksi pekerjaan dan lingkungannya. Keselamatan kerja adalah suatu keadaan yang aman dan keselamatan dari penderitaan dan kerusakan serta kerugian di tempat kerja, baik pada saat memakai alat, bahan, mesin-mesin dalam proses pengolahan, teknik pengepakan, penyimpanan, maupun menjaga dan mengamankan tempat serta lingkungan kerja. Secara harfiah K3 merupakan suatu usaha untuk menciptakan keadaan lingkungan kerja yang aman, bebas dari kecelakaan (control of accident). Kemampuan untuk mengidentifikasi, mengurangi,dan mengendalikan resiko yang tidak bisa diterima (the ability to identify and eliminate unacepptable risks). Kecelakaan sendiri adalah suatu kejadian atau peristiwa yang tidak diinginkan atau tidak disengaja serba tiba-tiba dan menimbulkan kerugian baik harta (material) maupun jiwa/manusia. Secara hakiki kesehatan dan keselamatan kerja merupakan upaya atau pemikiran serta penerapan yang ditujukan untuk menjamin keutuhan dan kesempurnaan baik jasmani maupun rohaniah tenaga kerja khususnya dan manusia pada umumnya. Hasil karya dan budaya, untuk meningkatkan kesejahteraan tenaga kerja (Kuswana, 2014). K3 
merupakan suatu upaya perlindungan dari kecelakaan agar tenaga kerja selalu dalam keadaan selamat dan sehat selama melakukan pekerjaan di tempat kerja serta bagi orang lain yang memasuki tempat kerja maupun sumber sehingga proses produksi dapat secara aman dan efisien dalam pemakaiannya.

Kesehatan kerja adalah upaya penyerasian antara kapasitas kerja, beban kerja dan lingkungan kerja agar setiap pekerja dapat bekerja secara sehat tanpa membahayakan dirinya sendiri maupun masyarakat di sekelilingnya, agar diperoleh produktivitas kerja yang optimal khusus di bidang Otomotif (Marji, 2012). Kesehatan kerja diselenggarakan untuk mewujudkan produktifitas kerja yang optimal. Kesehatan kerja meliputi pelayanan kesehatan kerja, pencegahan penyakit akibat kerja, dan syarat kesehatan kerja. Setiap tempat kerja wajib menyelenggarakan kesehatan kerja. Ketentuan mengenai kesehatan kerja sebagaimana dimaksud dalam ayat (2) dan (3) ditetapkan dengan Peraturan Pemerintah (PP). Tuntutan pekerjaan yang semakin kompleks disertai penggunaan teknologi yang makin canggih selain menyebabkan kenyamanan dan kemudahan dalam bekerja, tetapi juga mengandung resiko bahaya yang lebih besar akibat penggunaan bahan, alat dan teknologi. Bahaya-bahaya yang dapat mengancam antara lain kecelakaan kerja, pencemaran udara, kebisingan, dan kebakaran. Semua masalah yang disebutkan perlu ditangani melalui berbagai upaya peningkatan keselamatan dan kesehatan kerja dalam bentuk usaha pencegahan.

Tujuan utama dalam kesehatan dan keselamatan kerja adalah mengamankan suatu sistem kegiatan/pekerjaan mulai dari input, proses sampai dengan output. Kegiatan yang dimaksud bias berupa kegiatan produksi di dalam industri maupun di luar industri seperti sektor publik dan lain-lain. Penerapan program keselamatan kerja juga diharapkan dapat meningkatkan kesejahteraan (well-being). Perhatian inti terhadap K3 mencakup beberapa hal antara lain: penerapan prinsip-prinsip sains(application of scientific principles); pemahaman pola resiko (understanding the nature of risk); ruang lingkup ilmu K3 cukup luas baik di dalam ataupun di luar industri; K3 merupakan multidisiplin profesi; ilmu dasar yang terlibat dakam keilmuan K3 adalah fisik, kimia, biologi, dan ilmu-ilmu perilaku; dan area garapan: industri, transportasi, penyimpanan dan pengelolaan material, domestik, dan penyakit akibat kerja.

\section{METODE PENELITIAN}

Metode penelitian yang digunakan adalah metode deskriptif eksploratif. Penelitian deskripsi eksploratif untuk memberikan sedikit definisi atau penjelasan mengenai konsep 
atau pola yang digunakan dalam penelitian. Deskriptif eksploratif yang dimaksud yaitu untuk menggambarkan persepsi siswa di SMK Negeri 6 Bandung terhadap standar Kesehatan dan Keselamatan Kerja (K3) yang ada. Pendekatan yang digunakan dalam penelitian ini adalah penelitian kuantitatif, data yang terkumpul dan diolah dengan bantuan analisis statistik. Pengupulan data penelitian menggunakan teknik pengumpulan data dengan angket. Angket atau kuisioner (questionnaire) yang digunakan dengan cara mengumpulkan data secara tidak langsung (peneliti tidak langsung bertanya jawab dengan responden). Instrumen atau alat pengumpulan datanya berisi sejumlah pertanyaan atau pernyataan yang harus dijawab atau direspon oleh responden.

Teknik analisis data menggunakan statistik inferensial. Statistik ini digunakan untuk mendeskripsikan data dan tidak ingin membuat kesimpulan yang berlaku untuk populasi di mana sampel diambil. Untuk mengetahui tingkat kriteria, selanjutnya skor yang diperoleh (dalam \%) dianalisis dan dikonsultasikan dengan tabel kriteria.

\section{HASIL PENELITIAN}

Tingkat pemahaman siswa di SMK Negeri 6 Bandung tentang Kesehatan dan Keselamatan Kerja (K3) ketika berada di lapangan/workshop diukur tingkat persentasenya. Data yang diperoleh menunjukkan sebanyak 69,6\% siswa kelas XII menyatakan bahwa sudah memahami tentang K3. Sehinggan dapat dinyatakan bahwa siswa mamahami tentang K3 ketika berada di lapangan/workshop.

Persepsi siswa terhadap penerapan keselamatan kerja pada mata diklat memperbaiki roda dan ban, untuk indikator pengangkatan benda kerja secara manual adalah baik. Dimana sebanyak 9 orang (40\%) responden menyatakan setuju bahwa siswa dapat memahami melakukan pengangkatan benda kerja secara manual. Tiga orang (16\%) responden menyatakan sangat setuju. Enam orang (30\%) responden menyatakan kurang setuju. Tiga orang $(12,5 \%)$ responden menyatakan tidak setuju dan tidak ada responden yang menyatakan sangat tidak setuju. Sehinggan dapat dinyatakan bahwa siswa dapat memahami pengangkatan benda kerja secara manual. Dapat disimpulkan bahwa siswa udah memahami pengangkatan benda kerja secara manual dengan baik.

Persentase persepsi siswa untuk rambu-rambu K3, penanganan dan penanggulangan kecelakaan kerja adalah 69,8\%. Hasil perhitungan tersebut dapat diketahui sebanyak 69,8\% siswa menyatakan bahwa K3 yang terdapat disekolah sudah memahami rambu-rambu K3, penanganan dan penanggulangan kecelakaan kerja. Penilaian terhadap rambu-rambu $\mathrm{K} 3$, penanganan dan penanggulangan kecelakaan kerja tentang $\mathrm{K} 3$ 
ketika berada di lapangan/workshop adalah baik. Dimana sebanyak 10 orang (51\%) responden menyatakan setuju bahwa sudah memenuhi standar industri dalam praktiknya. Satu orang $(5,5 \%)$ responden menyatakan sangat setuju. Enam orang $(32,5 \%)$ responden menyatakan kurang setuju. Dua orang (9\%) responden menyatakan tidak setuju dan $2 \%$ responden yang menyatakan sangat tidak setuju. Sehinggan dapat dinyatakan bahwa siswa dapat memahami rambu-rambu K3, penanganan dan penanggulangan kecelakaan kerja. Kesimpulannya bahwa siswa sudah memahami rambu-rambu K3, penanganan dan penanggulangan kecelakaan kerja dengan baik.

\section{PEMBAHASAN}

Pemahaman siswa di SMK Negeri 6 Bandung tentang Kesehatan dan Keselamatan Kerja (K3) ketika berada di lapangan/workshop diukur tingkat persentasenya sudah baik yaitu sebanyak 69,6\%. Dengan demikian, sudah menjadi modal dasar bagi siswa untuk dalam memahami tentang K3. Namun, masih harus terus dilatih dan ditingkatkan lagi sampai dengan nilai tertinggi yang bisa dicapai. Hal ini sangat penting karena kemampuan ini akan digunakan olehs siswa ketika bekerja di industri atai menjadi wirausaha. K3 merupakan tuntutan bagi setiap pelaku industri dalam bekerja. Tidak menerapkan K3 akan menimbulkan kecelakaan kerja dan produktifitas bisa menurun (Sutrisno dan Ruswandi, 2007).

Persepsi siswa terhadap penerapan keselamatan kerja pada mata diklat memperbaiki roda dan ban secara manual bekategori baik dengan presentase sebanyak (56\%). Sebagai calon pekerja atau teknisi seharunya mempersiapkan diri dengan kemampuan dalam menerapkan K3. Hampir semua industri, besar atau kecil sudah wajib menerapkan K3 sesuai dengan undang-undang ketenagakerjaan. Berlatih menerapkan K3 di sekolah merupakan keharusan sebagai sarana latihan. Meskipun persepsinya masih paspasan, namun dengan bimbingan guru dan terus berlatih akan dicapai kemampuan yang terus meningkat.

Persepsi siswa tentang rambu-rambu K3, penanganan dan penanggulangan kecelakaan kerja sudah sesuai dengan standar industri dalam praktiknya dinyatakan baik yaitu sebanyak 69,8\%. Simbol dan rambu-rambu K3 menjadi sangat penting dalam bidang industri. Apalagi industri tersebut menggunakan teknologi tinggi dan beresiko tinggi. Kemampuan membaca simbol dan rambu-rambu k3 menjadi keharusan bagi setiap lulusan SMK. Simbol dan rambu-rambu biasa berlaku umum atau universal, sehingga disemua industri akan ditemui. Kemampuan ini masih harus terus diringkatkan dan diasah. 


\section{KESIMPULAN}

Pemahaman siswa tentang K3 ketika berada di lapangan/workshop dinyatakan dalam kondisi sudah baik. Standar K3 siswa SMK Negeri 6 Bandung sudah memenuhi standar K3 di industri. Hal ini ditunjukkan dengan data yang diperoleh melalui perhitungan angket yaitu pada kondisi baik. Sebagian besar siswa kelas XII TKR yang menyatakan telah sesuai dengan standar yang ada di industri. Tingkat pemahaman siswa kelas XII TKR terhadap rambu-rambu K3 dan upaya penanganan dan penanggulangan kecelakaan kerja yang kemungkinan terjadi di lapangan sudah sesuai. Hal ini ditunjukan dengan data yang diperoleh melalui perhitungan angket yaitu pada kondisi baik.

\section{DAFTAR PUSTAKA}

Anizar. (2009). Teknik Keselamatan dan Kesehatan Kerja di Industri. Yogyakarta: Graha Ilmu.

Depdiknas. (2005) Mengikuti Prosedur Kesehatan, Keselamatan Kerja dan Lingkungan. Direktorat Pembinaan Sekolah Kejuruan. Tidak Diterbitkan.

Kuswana, W. S (2014). Ergonomi dan K3 (Kesehatan dan Keselamatan Kerja). Cetakan Pertama. Bandung: PT. Remaja Rosdakarya.

Kuswana, W. S (2015). Pencegahan \& Pertolongan Pertama Pada Kecelakaan. Cetakan Pertama. Bandung: PT. Remaja Rosdakarya.

Marji. (2012). Kesehatan dan Keselamatan Kerja di Bidang Otomotif: Teknologi, keamanan dan Polusinya. Kementrian Pendidikan dan Kebudayaan. Universitas Negeri Malang (UM). Malang.

Sudjana (2005). Dasar-dasar Proses Belajar Mengajar. Bandung: PT. Remaja Rosdakarya.

Sutrisno dan Ruswandi, K. (2007). Prosedur Keamanan, Keselamatan dan Kesehatan Kerja. Sukabumi: Yudhistira. 